Provided for non-commercial research and education use. Not for reproduction, distribution or commercial use.

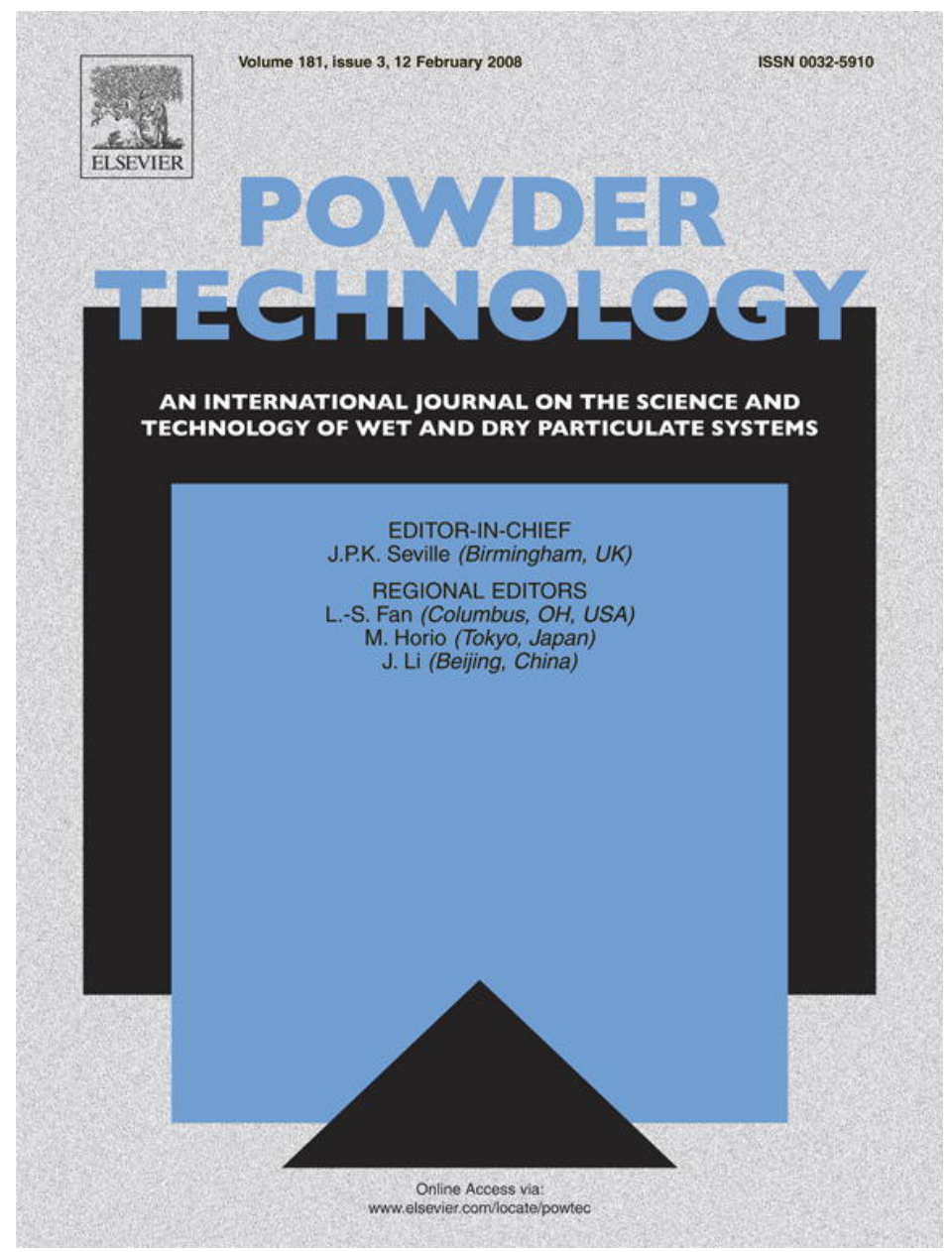

This article was published in an Elsevier journal. The attached copy

is furnished to the author for non-commercial research and education use, including for instruction at the author's institution, sharing with colleagues and providing to institution administration.

Other uses, including reproduction and distribution, or selling or licensing copies, or posting to personal, institutional or third party websites are prohibited.

In most cases authors are permitted to post their version of the article (e.g. in Word or Tex form) to their personal website or institutional repository. Authors requiring further information regarding Elsevier's archiving and manuscript policies are encouraged to visit: 


\title{
Fluidization of Group B particles with a rotating distributor
}

\author{
C. Sobrino*, J.A. Almendros-Ibañez, D. Santana, M. de Vega \\ Departamento de Ingeniená Térmica y de Fluidos, Universidad Carlos III de Madrid, Avda. de la Universidad 30, 28911 Leganés, Madrid, Spain
}

Received 23 May 2006; received in revised form 2 May 2007; accepted 17 May 2007

Available online 24 May 2007

\begin{abstract}
A novel rotating distributor fluidized bed is presented. The distributor is a rotating perforated plate, with $1 \%$ open-area ratio. This work evaluates the performance of this new design, considering pressure drop, $\Delta p$, and quality of fluidization. Bed fluidization was easily achieved with the proposed device, improving the solid mixing and the quality of fluidization.

In order to examine the effect of the rotational speed of the distributor plate on the hydrodynamic behavior of the bed, minimum fluidization velocity, $U_{\mathrm{mf}}$, and pressure fluctuations were analyzed. Experiments were conducted in the bubbling free regime in a $0.19 \mathrm{~m}$ i.d. fluidized bed, operating with Group B particles according to Geldart's classification. The pressure drop across the bed and the standard deviation of pressure fluctuations, $\sigma_{\mathrm{p}}$, were used to find the minimum fluidization velocity, $U_{\mathrm{mf}}$. A decrease in $U_{\mathrm{mf}}$ is observed when the rotational speed increases and a rise in the measured pressure drop was also found. Frequency analysis of pressure fluctuations shows that fluidization can be controlled by the adjustable rotational speed, at several excess gas velocities.

Measurements with several initial static bed heights were taken, in order to analyze the influence of the initial bed mass inventory, over the effect of the distributor rotation on the bed hydrodynamics.
\end{abstract}

(C) 2007 Elsevier B.V. All rights reserved.

Keywords: Fluidized bed; Rotating distributor; Hydrodynamics; Pressure fluctuations; Minimum fluidization velocity

\section{Introduction}

Fluidized beds present high mass and heat transfer rates what make them suitable in many industrial gas-solid applications (such as drying and granulation) as well as in the combustion, pyrolysis or gasification of many solid fuels, where they offer advantages over other types of reactors. Nevertheless, depending on the application, fluidization is sometimes difficult to achieve due to the agglomeration or cohesion between particles and defluidization or non-uniform fluidization may occur.

The non-homogeneous structures found in industrial fluidization processes have been studied by many investigators who have analyzed, among others, the influence of the particle size distribution and the bed pressure $[1,2]$ or the effect of the type of gas distributor [3] on the hydrodynamics of gas fluidized beds. The difficulty to fluidize A and C particles, as well as the need to maintain a good mixing between phases and a high particle dispersion, has led many investigators to modify the conven-

\footnotetext{
* Corresponding author. Tel.: +34 916248884; fax: +34 916249430.

E-mail address: csobrino@ing.uc3m.es (C. Sobrino).
}

tional fluidized bed devices, alter the air supply system or try innovative designs. Flow pulsation to control the bubble size and enhance the quality of fluidization has been used in a few experimental studies [4]. In a fluidized bed, pulsation can be introduced by several methods: intermittent air supply, sonic waves or vibration. Vibrated beds [5-7] have been extensively tested to fluidize $\mathrm{A}$ and $\mathrm{C}$ particles. The vibration imparted to the bed breaks the stable fixed channels that appear when operating with these groups of particles, and a better mixing between gas and particles in the bed is achieved. Minimum fluidization velocity becomes lower for vibrating fluidized beds and the pressure tends to decrease at incipient fluidization. A similar decrease in minimum fluidization velocity is obtained for Group B particles in sound assisted beds [8,9]. In this case, the pressure in the bed does not change. Low-frequency vibrations have also been applied in gas-liquid fluidized bed, turning out in smaller bubbles to be generated in the distributor [13]. Providing the different nature of gas-solid and gas-liquid fluidized beds, there are studies that show analogies in the hydrodynamic behavior of gas-solid and gas-liquid fluidized beds [14]. 


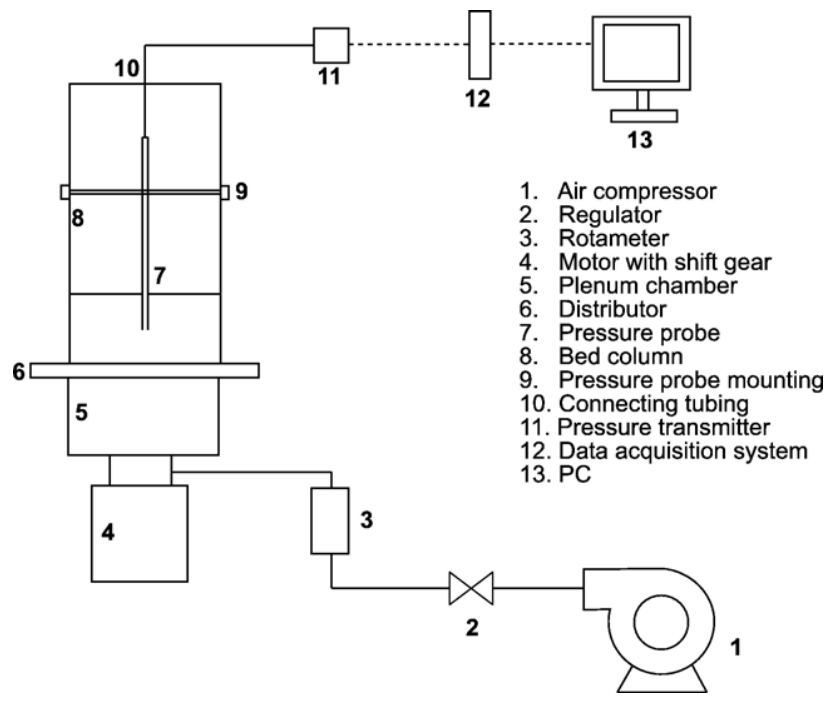

Fig. 1. Schematic diagram of the experimental fluidized bed.

Other investigators have tried to overcome the difficulties in mixing between phases and between solids in the bed, by modifying the distributor layout. In the spiral distributor [10] and its improved version [11], the gas enters the bed tangentially through overlapping blades shaped as full sectors of a circle, welded at the center. This configuration imparts a swirling motion to the solids. This horizontal convective movement of the particles improves the radial mixing of solids and the gassolids contact. This effect is restricted to the lower part of the bed and its complete effectiveness is only appreciable in shallow fluidized beds. A similar effect is found in the swirling distributor [12] where the swirling fluidizing pattern is generated by a multi-horizontal nozzle distribution in the plate.

The present design consists on a rotational distributor plate, whose aim is to overcome low radial gas mixing and particle dispersion, and to achieve a more uniform fluidization. Other investigators $[15,16]$ found a more uniform concentration gradient in the radial direction using rotating distributor plates. A decrease of the mean bubble diameter by increasing the rotational frequency of a porous plate distributor, has also been observed in generation of micro-air-bubbles in gas-liquid experiments [17].

The rotating distributor offers the advantages found in both, the swirling designs, that improved solid mixing and achieved the fluidization even for very shallow beds and the vibrating and sound assisted beds where the minimum fluidization velocity decreases. Besides, its design is simpler than the sound assisted or vibrated beds ones. Furthermore, the possibility to control and adjust the rotational speed of the distributor plate offers a wider range of operating conditions while maintaining the quality of fluidization.

The effect of the distributor plate rotation on the structure of a fluidized bed operated with Group B particles was experimentally studied: the influence of the rotational speed on the minimum fluidization velocity, the standard deviation of pressure fluctuations and the hydrodynamic characteristics of the bed are presented. It was found that the minimum fluidization velocity decreases as the rotational speed increases and a change in the pressure drop was also noticed. Experiments were carried out at several static bed heights, in order to detect the bed depth limit beyond which the influence of the distributor rotation is negligible.

\section{Experiments}

The schematic diagram of the test rig is given in Fig. 1. The experimental set-up consists of a transparent cylinder with $0.192 \mathrm{~m}$ i.d. and a height of $0.8 \mathrm{~m}$.

The rotating distributor is a perforated plate with $2 \mathrm{~mm}$ holes, giving a total open area ratio of $1 \%$. The plate is covered with a fine-mesh net to prevent particles from falling down through the plate into the wind-box. The holes are laid out in hexagonal pitch of $15 \mathrm{~mm}$. A spiral pitch distributor with the same open area ratio was also tested. At the bed axis, the distributor is coupled with the driveshaft of an AC electric motor with a 1:15 reducer. The rotational speed can be controlled using a frequency inverter and it ranges from 0 to $100 \mathrm{rpm}$. A detail of the mechanical set-up and the design of the distributor plates are shown in Fig. 2.

The bed was filled with Geldart B silica sand particles with a mean diameter of $300 \mu \mathrm{m}$ and a density of $2600 \mathrm{~kg} / \mathrm{m}^{3}$. The settled bed heights were varied from $L / D=0.35$ to $L / D=0.75$, corresponding to bed inventories of $2 \mathrm{~kg}$ to $6 \mathrm{~kg}$ of sand. The air flow rate was measured with a rotameter. The volumetric flow rates ranged from $01 / \mathrm{min}$ to $1400 \mathrm{l} / \mathrm{min}$, resulting in a fluidizing velocity of 0 to $0.8 \mathrm{~m} / \mathrm{s}$.

Pressure measurements were taken in the bed. The pressure sensor was initially placed flush to the bed wall. Nevertheless, the pressure fluctuations series showed a periodic cycle due to the distributor rotating frequency, what hindered the analysis of

(a)

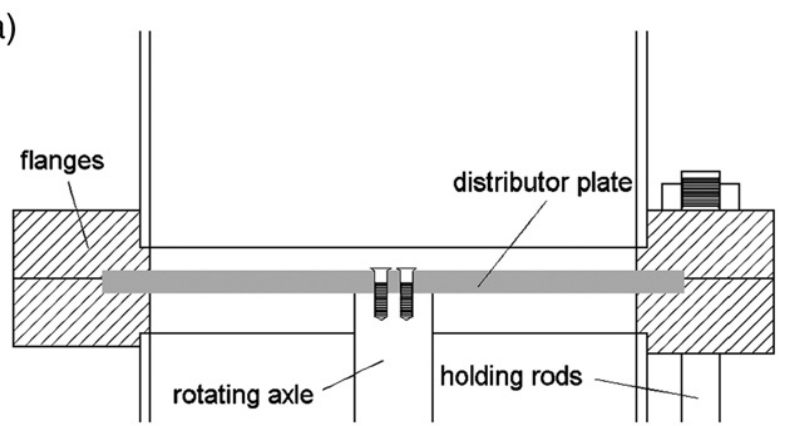

(b)

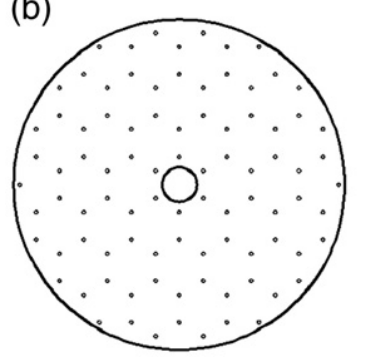

(c)

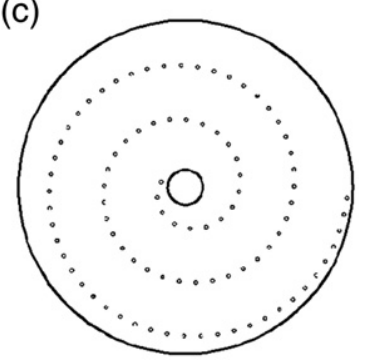

Fig. 2. (a) Detail of the mechanical set-up of the rotating distributor. (b) Uniform pitch distributor. (c) Spiral pitch distributor. 


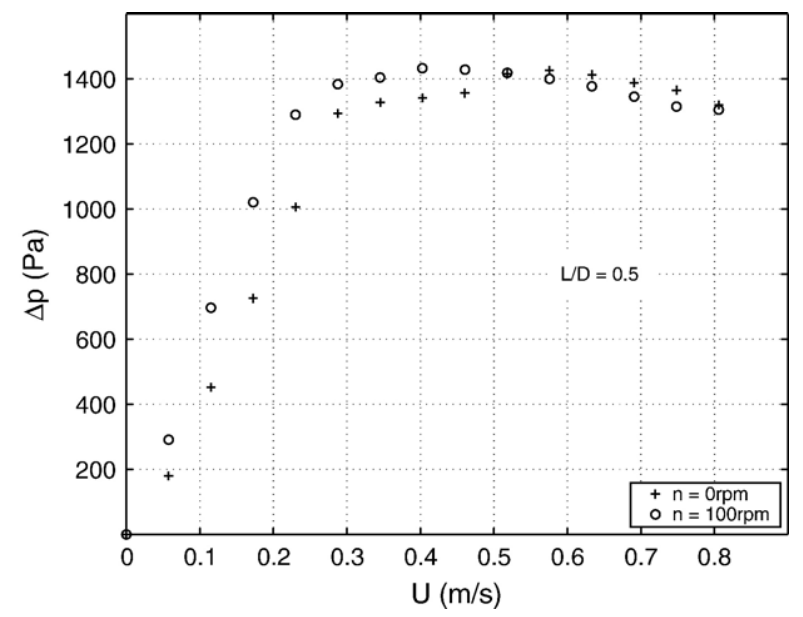

Fig. 3. Pressure drop across the bed, $\Delta p$, as a function of the superficial gas velocity, $U$, for $n=0 \mathrm{rpm}$ and $n=100 \mathrm{rpm}$.

the frequency distribution in the fluidized bed. To avoid this problem the pressure probe was mounted at the bed axis [18]. The pressure drop across the bed and the pressure oscillations were measured with an Omega PX 291 piezoresistive differential pressure transmitter $\left(0-5\right.$ in $\left.\mathrm{H}_{2} \mathrm{O}\right)$ with a $1 \% \mathrm{FS}$ accuracy. The sensor was mounted on a $5 \mathrm{~mm}$ i.d. steel probe and silicone connecting tubing of $4 \mathrm{~mm}$ i.d. and the whole setup had a length of about $2 \mathrm{~m}$. According to Xie and Geldart [19], the response time of the probe-transducer set-up depends mainly on the diameter of the probe and the connecting line. The probe used in the experiment proved to give a fast response without notably distorting the bubble path. The measurements were taken about $5 \mathrm{~cm}$ below the bed surface, roughly in the middle of the bed height. The high pressure port is placed at this point and the low pressure port is exposed to atmosphere. The tip of the pressure probe was covered with a fine-mesh net at the side facing of the fluidized bed in order to avoid the fine particles going into the tube. The data were recorded with a 12 bits data acquisition board (ICP DAS PCI$1802 \mathrm{H}$ ) assembled in a PC. The resultant accuracy in pressure measurements was approximately $\pm 12 \mathrm{~Pa}$. Time series of 12000 data points measured with a sample frequency of $200 \mathrm{~Hz}$ were processed to obtain standard deviations and power spectral density functions.

\section{Results and discussion}

Pressure measurements were used to examine the effect of the rotational speed of the distributor plate on the hydrodynamic behavior of the bed. The following aspects were evaluated:

(1) The pressure drop across the bed over a wide range of gas velocities.

(2) The minimum fluidization velocity $U_{\mathrm{mf}}$ calculated with the standard deviation of pressure fluctuations, $\sigma_{\mathrm{p}}$.

(3) The response of the bed in the frequency domain. Additional experiments were carried out at several fixed bed heights to find out the bed height up to which the global effect of the rotation is still perceptible.

\subsection{Effect of the rotational speed on the hydrodynamic behavior of the bed}

\subsubsection{Minimum fluidization velocity}

The pressure drop across the bed was measured at a range of superficial gas velocities, $U$, beginning with a vigorously fluidized bed and reducing to zero velocity. All measurements were taken decreasing the flow rate, in order to avoid the hysteresis that appears when the velocity is increased from $U=0 \mathrm{~m} / \mathrm{s}$. This hysteresis is due to the wedging action within the fixed bed [20]. Fig. 3 compares the measured pressure drop for the distributor plate rotating at the maximum rotational speed $(n=100 \mathrm{rpm})$ with the measurements without rotation.

When the distributor plate rotates, $U_{\mathrm{mf}}$ decreases, and a moderate increase in the pressure drop is found, for gas velocities below $2 U_{\mathrm{mf}}$. The rise in the pressure drop is in agreement with the results of other investigators [15]. The change in this trend, when operating at higher gas flows, can be attributed to a predominant influence of the axial gas velocity, as opposed to the tangential velocity imparted by the distributor rotation to the bed.

The method used above for the experimental determination of the minimum fluidization velocity needs measurements made in both, free bubble fluidization and fixed bed regimes, including the complicated transition region.

A better estimate of $U_{\mathrm{mf}}$ for Geldart B particles is obtained using a second method consisting on measuring the pressure fluctuations in the bed [21-23]. Fig. 4 shows the standard deviation of pressure fluctuations, $\sigma_{\mathrm{p}}$, for a range of gas velocities at several rotational speeds. $U_{\mathrm{mf}}$ is calculated for each rotational speed by the intercept of the extrapolated line with the $U$ axis $\left(\sigma_{\mathrm{p}}=0\right)$. The least squares method was used to calculate the linear relationship between $\sigma_{\mathrm{p}}$ and $U$. Fits with an $R$-square greater than 0.98 were obtained.

The values of $U_{\mathrm{mf}}$ at each rotational speed, normalized with respect to $U_{\mathrm{mf}}$ for the static distributor configuration, $U_{\mathrm{mf}_{0}}$, are plotted in Fig. 5 against the centripetal acceleration, $\omega^{2} R_{\mathrm{m}}(\omega$ is the angular velocity of the distributor plate and $R_{\mathrm{m}}$ is its average radius), nondimensionalized with the gravitational acceleration,

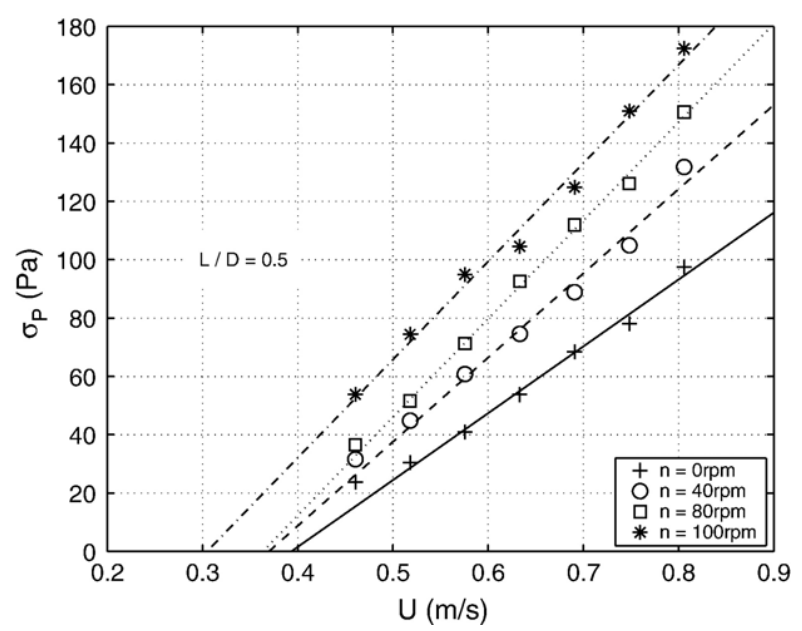

Fig. 4. Standard deviation of pressure fluctuations, $\sigma_{\mathrm{p}}$, for several rotational speeds, n, against gas velocity, $U$. 


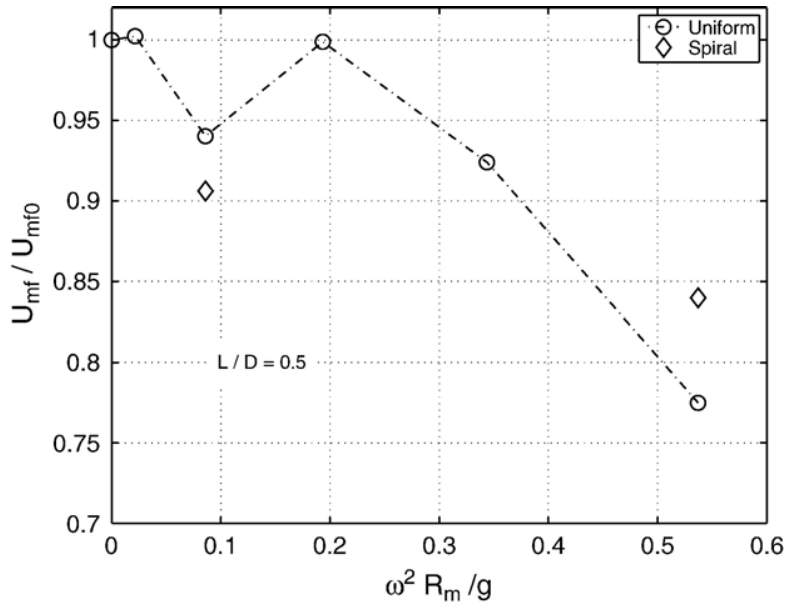

Fig. 5. $U_{\mathrm{mf}^{\mathrm{f}}} / U_{\mathrm{mf}_{0}}$ against the nondimensional centripetal acceleration of the distributor plate, $\omega^{2} R_{\mathrm{m}} / g$.

$g$. The value $\omega^{2} R_{\mathrm{m}} / g$ is proportional to the quotient between the centrifugal force and the buoyancy force acting on the bubbles ascending through the bed. It is shown that the decrease in $U_{\mathrm{mf}}$ is higher as the angular velocity of the distributor plate, $\omega$, increases. For low values of $\omega$ a negligible effect was found.

A second hole layout in the distributor plate was experimented besides the triangular pitch. It consisted on a spiral pitch layout. The experiments suggested a worse performance compared with the triangular pitch layout (holes uniformly distributed). However the same trend was found with regard to the $U_{\mathrm{mf}}$ decrease when the distributor plate rotates, as also shown in Fig. 5.

To compare the performance of the bed at several rotational speeds but at the same fluidization regime, gas velocity $U$ is nondimensionalized with the minimum fluidization velocity for the respective rotational speed. This approach is shown in Fig. 6, where it can be seen a very similar amplitude of pressure fluctuations, $\sigma_{\mathrm{p}}$ against $U / U_{\mathrm{mf}}$ for several rotational speeds. This result indicates that the fluidization quality is very similar independently of the rotational speed for the same excess gas $U /$ $U_{\mathrm{mf}}$. However, this similarity tends to disappear for an excess gas about $U / U_{\mathrm{mf}}=1.6$.

The bed behavior using the novel rotating design could be advantageous for partial oxidation processes in fluidized beds (e.g., coal gasification) operating in the free bubbling regime, as the proposed design would enable to fluidized the bed more easily, even in the case of particle agglomeration due to the low melting point of some compounds. The fluidization might more closely resemble particulate than bubbling fluidization. Besides that, the rotation would add a new free parameter which allows to operate with a lower air rate keeping the desired excess air ratio.

\subsubsection{Frequency domain analysis}

According to Johnsson et al. [24], the amplitude of pressure fluctuation signals expressed as standard deviation, is not sufficient to quantify the bed dynamics and in some cases can be misleading. A change in amplitude can be caused by a redistribution of solids in the fluidized bed without any significant

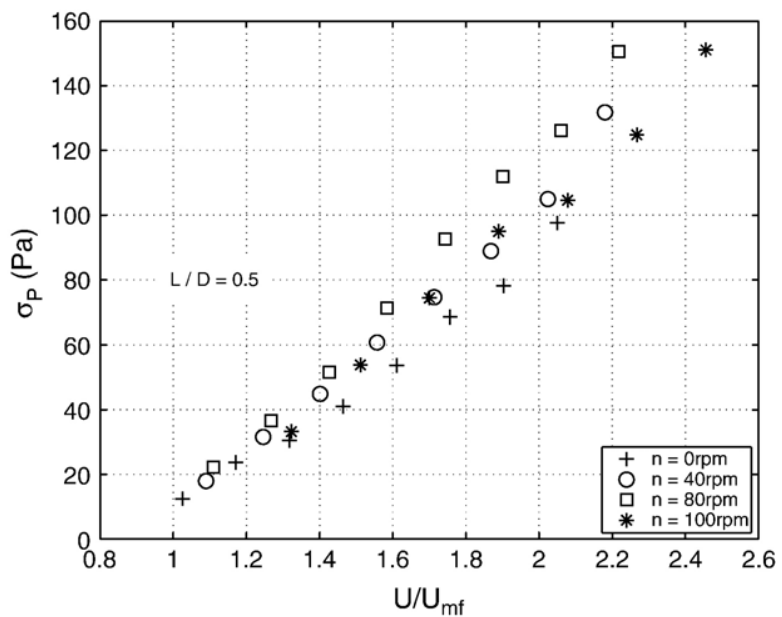

Fig. 6. Standard deviation of pressure fluctuations, $\sigma_{\mathrm{p}}$, for several rotational speeds against the excess gas $U / U_{\mathrm{mf}}$.

change in the dynamics of the flow. Spectral analysis may give a quite different picture from that of amplitude analysis. Therefore analysis of frequency distribution of pressure time series is also discussed.

Welch method is used for power spectrum estimation [25]. A hamming window is chosen as window function. All subspectra are based on 4096 samples yielding an average of 8 subspectra.

The power spectra of pressure time series of the static distributor and the rotating distributor, have been compared for the same gas velocity, in order to determine the gas flow needed to fluidize the bed. Fig. 7 shows the power spectra for a gas velocity close to $U_{\mathrm{mf}}$ at $n=100 \mathrm{rpm}(U=0.3 \mathrm{~m} / \mathrm{s})$. At this gas velocity bubbles are detected when the distributor plate rotates. However, using the static distributor, no bubbles are found. It is confirmed that a lower gas velocity is needed to fluidize the bed when the rotating distributor is used.

The influence of the rotational speed of the distributor plate in the bed dynamics was analyzed at a given excess gas $U / U_{\mathrm{mf}}$.

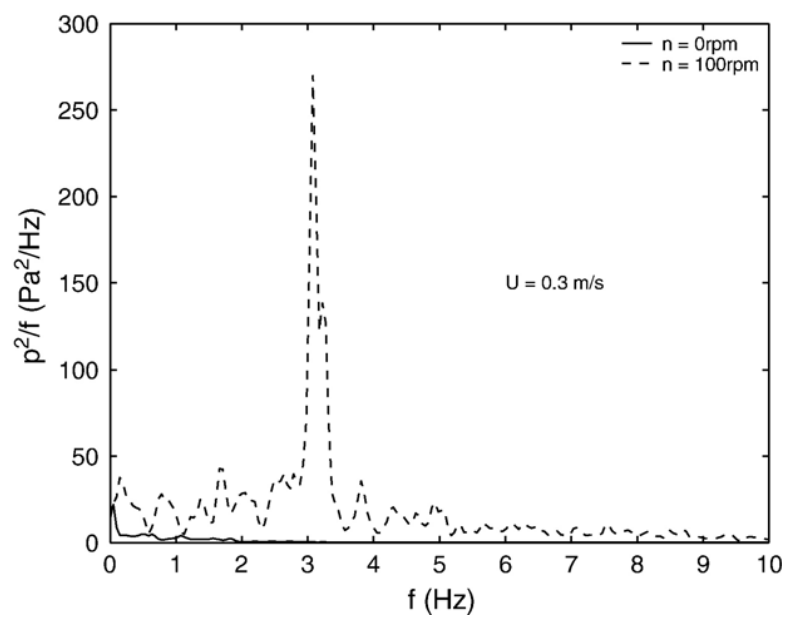

Fig. 7. Power spectra for a gas velocity $U=0.3 \mathrm{~m} / \mathrm{s}$ and a fixed bed height $L /$ $D=0.5$ at $n=0 \mathrm{rpm}$ and $n=100 \mathrm{rpm}$. 
(a)

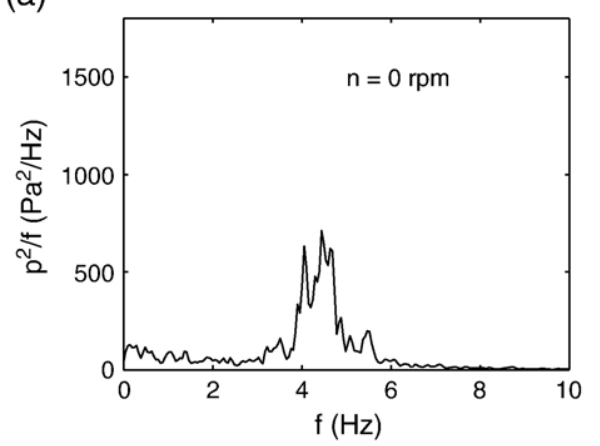

(c)

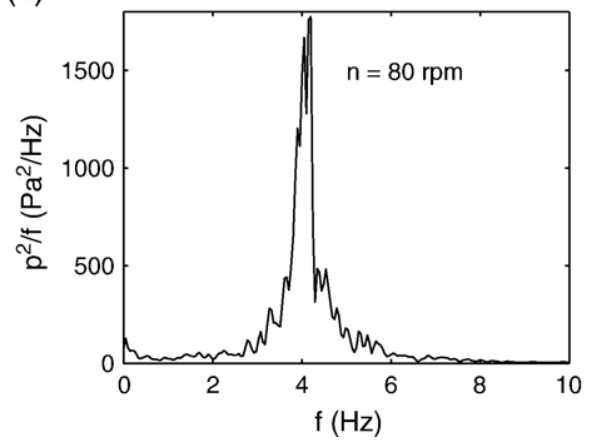

(b)

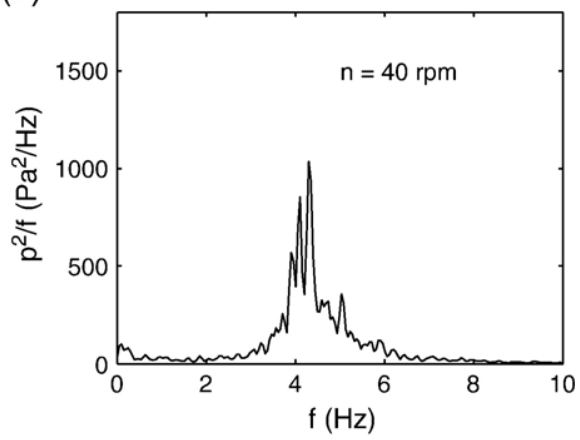

(d)

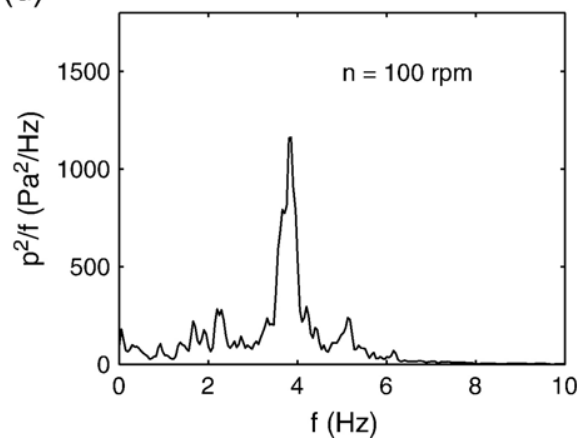

Fig. 8. Power spectra: (a) $n=0 \mathrm{rpm}$, (b) $n=40 \mathrm{rpm}$, (c) $n=80 \mathrm{rpm}$ and (d) $n=100 \mathrm{rpm}$, fixed bed height $L / D=0.5$ and excess gas $U / U_{\mathrm{mf}}=1.3$.

Fig. 8 shows the first $10 \mathrm{~Hz}$ (of $100 \mathrm{~Hz}$ measured) of the bed power spectra for an excess gas flow of $U / U_{\mathrm{mf}}=1.3$, at 4 different rotational speeds.

A quite similar behavior in the frequency domain is shown at every distributor rotational speed. The same dominant frequen- cy of $4 \mathrm{~Hz}$ and an energy of the signals about $1000 \mathrm{~Pa}^{2} / \mathrm{Hz}$ are observed.

The influence of the rotational speed on the bed dynamics can be explained in terms of the relation between the tangential velocity, $\omega R_{\mathrm{m}}$, imparted to the flow by the distributor rotation

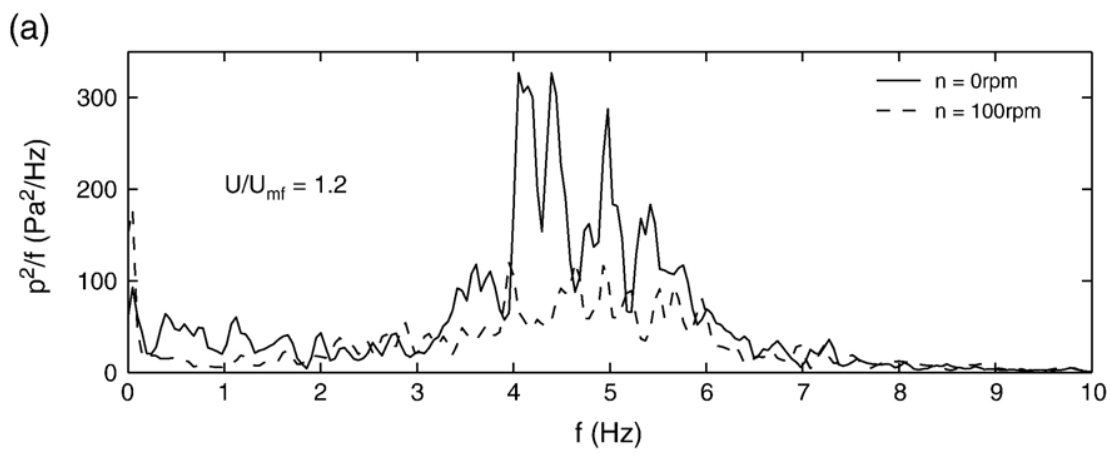

(b)

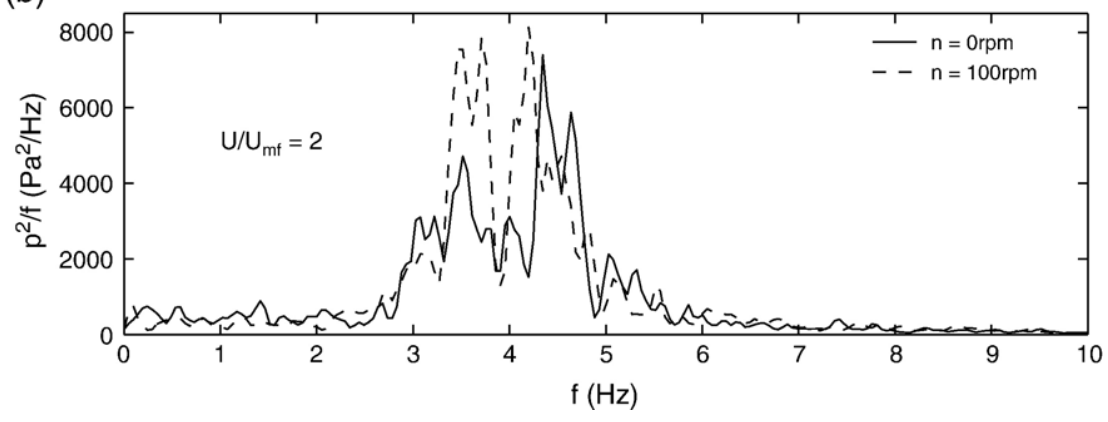

Fig. 9. Power spectra for an excess gas: (a) $U / U_{\mathrm{mf}}=1.2$, (b) $U / U_{\mathrm{mf}}=2$ and a fixed bed height $L / D=0.5$. 


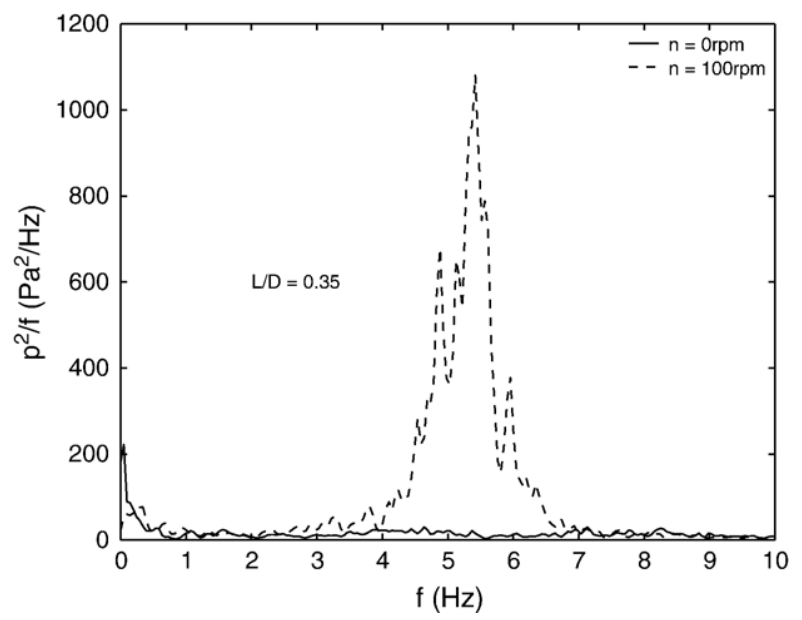

Fig. 10. Power spectra at $U / U_{\mathrm{mf}}=2$, fixed bed height $L / D=0.35, n=0 \mathrm{rpm}$ and $n=100 \mathrm{rpm}$.

and the superficial gas velocity, $U$, which has an axial direction. The average tangential velocity of the gas in contact with the distributor plate, $\omega R_{\mathrm{m}}$, is about $0.5 \mathrm{~m} / \mathrm{s}$ when the plate rotates at $100 \mathrm{rpm}$. This velocity value is about $1.6 U_{\mathrm{mf}}$. Accordingly, with gas velocities $U$, above $1.6 U_{\mathrm{mf}}$, the gas would have a predominantly axial direction. Otherwise, that is $U<1.6 U_{\mathrm{mf}}$, the effect of the tangential velocity imparted to the gas by the distributor would be dominant. Fig. 8 compares at $U / U_{\mathrm{mf}}=1.2$ (Fig. 9a) and $U / U_{\mathrm{mf}}=2$ (Fig. 9b) the power spectrum of pressure fluctuations for the static distributor, with the corresponding power spectrum of the distributor rotating at $100 \mathrm{rpm}$. It was already shown that if the tangential velocity is of the same order of the superficial gas velocity, the same amplitude of the pressure signal can be observed regardless of the rotational speed (Fig. 6). Moreover, attending to frequency domain tools, it is now shown that an smaller peak in the power spectrum is found when the rotating distributor (Fig. 9a) is used.

Nevertheless, the improvement in the quality of fluidization achieved with the novel distributor, tends to disappear when the tangential velocity, $\omega R_{\mathrm{m}}$, becomes smaller than the gas velocity. In Fig. 9b, at an excess gas of $U / U_{\mathrm{mf}}=2$, the gas flow supplied to the bed with the rotating distributor is such that $U>\omega R_{\mathrm{m}}$. In this case the standard deviation of pressure fluctuations has a higher amplitude for the rotating distributor configuration, as already shown in Fig. 6. However, using frequency domain analysis, power spectra of the same energy are found for both the static and the rotating distributor configurations. The dominant frequencies observed are also the same.

Comparing Fig. 9a and $\mathrm{b}$, a rise in the dominant frequency can be observed when the gas velocity increases for both rotational speeds.

The performance of the novel fluidized bed proposed in this paper has two main contributions. On the one hand, a lower gas flow is needed to fluidize the bed what is useful in applications with this request. On the other hand, a new operating parameter appears; if an specific value of the gas flow is required in practical applications, the bed dynamics can be controlled by adjusting the rotational speed of the distributor plate, without loosing the quality of the fluidization. In other words, at a fixed gas velocity a more vigorously fluidization can be achieved by increasing the rotational speed of the distributor while a lower bubble formation is achieved by decreasing the rotational speed.

\subsection{Effect of the bed height in the rotating distributor configuration}

Several studies have demonstrated that there is not a significant change in $U_{\mathrm{mf}}$ when the settled bed depth varies [26]. In order to study how the effect of the distributor rotation on the hydrodynamics of the bed is affected by the static bed height, experiments were carried out at several fixed bed heights with the static distributor and with the new distributor rotating at $n=100 \mathrm{rpm}$. For very shallow beds, $L / D \sim 0.25$, continuous gas channels are observed in the bed for the static distributor configuration. When the distributor plate rotates, the gas flow is locally interrupted and jets formed at each hole are broken, achieving a bubbling like fluidization. Visual observation of the flow at the wall of the column shows how particles and bubbles are dragged by the plate rotation, what together with the axial gas flow results in an helicoidal path of the bubbles along the bed.

Fig. 10 compares the power spectra of the rotating distributor configuration ( $n=100 \mathrm{rpm}$ ) with the static distributor configuration, both operating at the same gas velocity $U=2 U_{\mathrm{mf}}$ and fixed bed height $L / D=0.35$. The $U_{\mathrm{mf}}$ used to determine the gas flow rate $U / U_{\mathrm{mf}}$ are the values calculated in Section 3.1.1 for a fixed bed height $\mathrm{L} / \mathrm{D}=0.5$, since no change in $U_{\mathrm{mf}}$ with height is assumed. The power spectrum shows how the rotation makes the fluidization of the bed possible and a bubbling characteristic frequency of $5 \mathrm{~Hz}$ appears when using the distributor plate rotating at $100 \mathrm{rpm}$.

For a high enough bed height (about $L / D=0.5$ ) uniform fluidization is achieved with both, static and rotational distributor beds. Fig. 11 shows the trend of the minimum

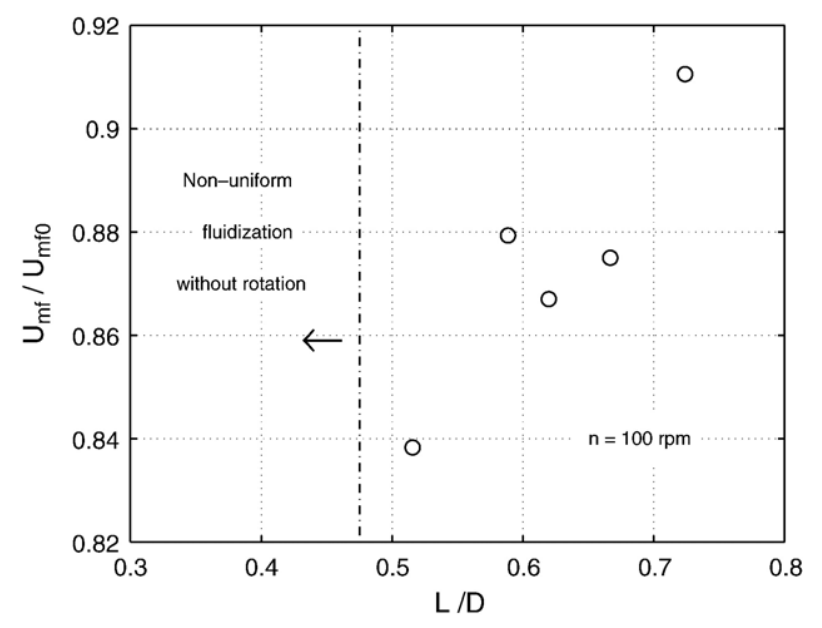

Fig. 11. $U_{\mathrm{mf}^{\prime}} / U_{\mathrm{mf}_{0}}$ relation against nondimensional bed height for a distributor rotational speed $n=100 \mathrm{rpm}$. 
fluidization velocity of the rotating distributor bed nondimensionalized with the minimum fluidization velocity of the static distributor bed, $U_{\mathrm{mf}_{0}}$, with the settled bed height. The rotation effect becomes less important when the bed height increases and it is globally negligible for bed heights over $L / D=0.75$. However, a local study of the bottom bed area would probably show an important effect of the rotation in this area independently of the bed height.

\section{Conclusions}

This study has shown the characterization of the proposed rotating distributor plate. This design is optimum when a feed stream of solids must be quickly dispersed all over the bed as they may be immediately horizontally transported by the rotation. The distributor plate rotation promotes an increase in the radial dispersion of the particles, reducing the high concentration zones present at the fluidized beds. This rapid mixing also prevents the temperature gradient, such as a hot spot near the feed point, in a fluidized bed combustor. Some differences were found in the hydrodynamics of the bed in relation to the classical static distributor:

(a) If $\omega^{2} R_{\mathrm{m}}>0.2 \mathrm{~g}$ the minimum fluidization velocity is $10 \%$ lower for the rotating distributor configuration and this value decreases when increasing $\omega$.

(b) If $\omega R_{\mathrm{m}} \sim U$ the same fluidization quality is found not depending on the rotational speed.

(c) If $\omega R_{\mathrm{m}}<U$ the effect of the plate rotation on the bed dynamics disappears due to the dominant influence of the axial gas velocity with respect to the tangential velocity caused by the distributor rotation.

(d) The rotation of the distributor allows to fluidize very shallow beds which had a jet structure when the static distributor was used; the effect of the rotation becomes globally less important for deeper beds.

These characteristics show that adjusting the rotational speed it is possible to change the gas velocity needed to fluidized the bed, facilitating the fluidization and maintaining an uniform fluidization.

Further work could investigate the performance of the rotating distributor in Geldart $\mathrm{A}$ and $\mathrm{C}$ particles which are more difficult to fluidized. Moreover, similar experiments could be carried out encouraging the effect of the rotation by increasing the rotational speed above $100 \mathrm{rpm}$, or modifying the holes layout on the distributor.
Notations
D Bed diameter (m)
$L \quad$ Height of fixed bed measured from the distributor (m)
$n \quad$ Rotational speed of the distributor plate (rpm)
$R_{\mathrm{m}} \quad$ Average radius of the distributor plate (m)
$U \quad$ Superficial gas velocity $(\mathrm{m} / \mathrm{s})$
$U_{\mathrm{mf}} \quad$ Minimum fluidization velocity $(\mathrm{m} / \mathrm{s})$
$U_{\mathrm{mf}_{0}} \quad$ Minimum fluidization velocity for the static distributor plate $(\mathrm{m} / \mathrm{s})$

$\Delta p \quad$ Pressure drop across the bed $(\mathrm{Pa})$

$\sigma_{\mathrm{p}} \quad$ Standard deviation of pressure fluctuations (Pa)

$\omega \quad \frac{2 \pi r}{60}$ Angular velocity of the distributor plate $\left(\mathrm{s}^{-1}\right)$

\section{Acknowledgements}

This work has been supported by the National Energy Programme of the Spanish Ministry of Education under the project number ENE2006-01401. One of the authors (C.S.) wish gratefully acknowledge Dr. N. Ellis and the Department of Chemical and Biological Engineering (University of British Columbia) for their helpful assistance during her research stay at the Fluidization Research Centre.

\section{References}

[1] J. Wiman, A.E. Almstedt, Influence of pressure, fluidization velocity and particle size on the hydrodynamics of a freely bubbling fluidized bed, Chemical Engineering Science 53 (1998) 2167-2176.

[2] P.A. Olowson, A.E. Almstedt, Influence of pressure and fluidization velocity on the bubble behavior and gas flow distribution in a fluidized bed, Chemical Engineering Science 45 (1990) 1733-1741.

[3] J. Werther, Effect of gas distributor on the hydrodynamics of gas fluidized beds, German Chemical Engineering 1 (1978) 166-174.

[4] N.A. Moussa, A.A. Fowle, M.M. Delichatsios, R.N. Caron, R.P. Wilson, Advanced design for pulsed atmospheric fluidized bed combustion, Final Rep. to DOE/METC, Morgantown Energy Technology Center, Morgantown, WV, 1982.

[5] E. Bratu, G.I. Jinescu, Effect of vertical vibrations on pressure drop in a fluidised layer, British Chemical Engineering 16 (1971) 691-695.

[6] Y. Mawatari, Y. Tatemoto, K. Noda, Prediction of minimum fluidization velocity for vibrated fluidized bed, Powder Technology 131 (2003) 66-70.

[7] K. Noda, Y. Mawatari, S. Uchida, Flow patterns of fine particles in a vibrated fluidized bed under atmospheric or reduced pressure, Powder Technology 99 (1998) 11-14.

[8] L.-P. Leu, J.-T. Li, C.-M. Chen, Fluidization of group B particles in an acoustic field, Powder Technology 94 (1997) 23-28.

[9] C.A. Herrera, E.K. Levy, Bubbling characteristics of sound-assisted fluidized beds, Powder Technology 119 (2001) 229-240.

[10] F. Ouyang, O. Levenspiel, Spiral distributor for fluidized beds, Industrial \& Engineering Chemistry Process Design and Development 25 (1986) 504-507.

[11] B. Sreenivasan, V.R. Ragahavan, Hydrodynamics of a swirling fluidised bed, Chemical Engineering and Processing 41 (2002) 99-106.

[12] C.-S. Chyang, Y.-C. Lin, A study in the swirling fluidizing pattern, Journal of Chemical Engineering of Japan 35 (6) (2002) 503-512.

[13] J. Ellenberger, R. Krishna, Shaken, not stirred, bubble column reactors: enhancement of mass transfer by vibration excitement, Chemical Engineering Science 58 (2003) 705-710.

[14] J. Ellenberger, R. Krishna, A unified approach to the scale-up of gas-solid fluidized bed and gas-liquid bubble column reactors, Chemical Engineering Science 49 (1994) 5391-5411.

[15] A. Esin, T. Cakaloz, Effect of distributor rotation on gas mixing in a fluidized bed, Powder Technology 23 (1979) 245-251.

[16] H.J. Elder, US Patent 2761769 (1956).

[17] S. Fujikawa, R. Zhang, S. Hayama, G. Peng, The control of micro-airbubble generation by a rotational porous plate, International Journal of Multiphase Flow 29 (2003) 1221-1236.

[18] K. Svoboda, J. Cermak, M. Hartman, J. Drahos, K. Selucky, Pressure fluctuations in gas-fluidized beds at elevated temperatures, Industrial \& Engineering Chemistry Process Design and Development 22 (1983) 514-520.

[19] H.-Y. Xie, D. Geldart, The response time of pressure probes, Powder Technology 90 (2) (1997) 149-151. 
[20] J.F. Davidson, D. Harrison, Fluidised Particles, Cambridge University Press, 1963.

[21] M. Puncochar, J. Drahos, J. Cermak, K. Selucky, Evaluation of minimum fluidizing velocity in gas fluidized bed from pressure fluctuations, Chemical Engineering Communications 35 (1985) 81-87.

[22] D. Wilkinson, Determination of minimum fluidization velocity by pressure fluctuation measurement, The Canadian Journal of Chemical Engineering 73 (1995) 562-565.

[23] J.V. Briongos, J.M. Aragón, M.C. Palancar, Fluidised bed dynamics diagnosis from measurements of low-frequency outbed passive acoustic emissions, Powder Technology 162 (2006) 145-156.
[24] F. Johnsson, R.C. Zijerveld, J.C. Shouten, C.M. van den Bleek, B. Leckner, Characterization of fluidization regimes by time-series analysis of pressure fluctuations, International Journal of Multiphase Flow 26 (2000) 663-715.

[25] P.D. Welch, The use of a fast Fourier transform for the estimation of power spectra, IEEE Trans. Audio and Electroacoustics AU-15, 1967, pp. 70-73.

[26] A. Delebarre, J.M. Morales, L. Ramos, Influence of the bed mass on its fluidization characteristics, Chemical Engineering Journal 98 (2004) 81-88. 